\title{
زيد بن علي (عليهما السلام) وهكانته في مصنفات شمال أفريقيا والأندلس
}

\author{
أ.م.د. سادسة هلاوي ممود / كلية الاداب / جامعة واسط \\ الباحث صبام عبد محمد / مديربة تربية واسط
}

\section{Abstract}

The status of Zaid Bin Ali (Peace be upon him) amongst scientists and historians of North Africa and Andalus .

Zaid Bin Ali (Peace be upon him) has legacy and honorable history through his preaches for justice and reformation. Thus scientists and biography writers viewed these opinions according to the wholly book and realized his honorable altitude so it was logical that they would mention his biography with great respect .

During his life time , Zaid Bin Ali ( peace be upon them ) was respected by his follow scientist and those who came after him. All those who knew him, as well as, who read about him appreciated his honesty, devotion for Allah and Ahl - Al Bait (peace be upon them), and his scientific abilities. Those who studied his biography agreed that he was a man of greatness that oblige others to respect him. It is evident that all bad stories and false information that was written about him proved to be wrong. In addition to the fact that such wrong information was meant to create hatred and that rage towards this great man. Thus it was natural that history will reveal reality at the end.

لزيد بن علي ( عليهما السلام ) شواهد و اثأر وخدمات شريفة ، ونصرة الحق ، ودعوته الهادفة

إلى الإصلاح و العدل ، لذلك نظر العلماء وأهل السير والآثار وأرباب المعاجم عن كثب إلى تلك المواقف لزيد بن علي ( عليهما السلام ) في الثريعة المقدة ، فأكثروا في ذكره والثناء عليه ، وحفظوا في مؤلفاتهم تلك المآثر البيضاء في أزمنة الدهر ـ واحتل زيد مكانه مرموقة لدى العلمـاء المعاصرين لـه ، و الذين أتوا بعده ، و عند المؤرخون الذين أرخوا لتلك الثخصية التي ملأت الأفاق في علمها وشجاعتها وحبها و إيثار هـا ، و الذين اجمعوا على تقدمه بالعلم على غيرة من العلماء ، وقد اتفق معظم هؤلاء على نز اهتهـ و إخلاصـه لله عز وجل و لأهل البيت ( عليهم السـلام ) ، وهتفوا بصوت واحد انهه من الأخيار السـابقين، وله هيبة تعنو لها الجباه، وتملاء النفوس إكبار ا و هي تضاهي هيبة إبائه التي كانت من أنوار النبوة والإمامة. وقد ارتفعت عنه كل حيرة وشبهة فيما حمله لنا رواة السوء من الأحاديث المغلوطة ، و أسس البغضاء و المصلحية و العداء التي ير اد منها النيل من عظمة تلك الثخصية، التي حملت كل تلك الصفات التي بإمكان كل شخص إن يحمها لو اتقى الله سبحانه وتعالى حق تقاتهـ ـ ويمكن معرفة مكانـة زيد (عليه السـلام) من خـلال هؤلاء العلمـاء و المؤرخين ، المعاصرين أو الذين جاءوا بعدة بقرون ، الذين كان لهم دور في نشر آثار العالم والفقيه والثائر والمجاهد زيد 
عامر بن شرحبيل الشعبي ('). كان الشعبي من المعجبين بزيد بن علي (عليهما السـلام) من خـلال شجاعته

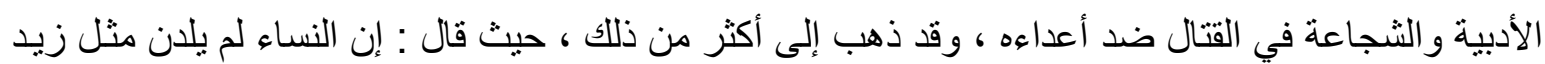
في الفقه و العلم (r)

أبو حنيفة النعمان (ॅ). عاش أبو حنيفة اثنان وخمسون سنة في العصر الأموي ، وثمان عثر سنة في العصر العباسي ، لذلك فهو أدرك الدولتين وكل ما مرت بهما خلال هذه السنين وتجلت له سطوت الدولة الأمويـة في في وني جبروتها وقوتها ومحاولتها قهر الثـعوب الإسـلامية والرجوع بها إلى الجاهلية، لذلك كان مسـاندا ومشجعا للحركات الثورية التي كانت تحدث ضد الحكمين الأموي و العباسي، ومن تلك الحركات و الثور ات العلويـة التي كانت قادتها أو من يديرها من اقرب المقربين للرسول محمد (صل الله عليه والـه وسلم) في أصولها ، و التي حاولت الإطاحة بالحكم الأموي أولا ، ومن ثم الحكم العباسي ثانيا ، و أدرك أبو حنيفة كل ذللك فكان لـه

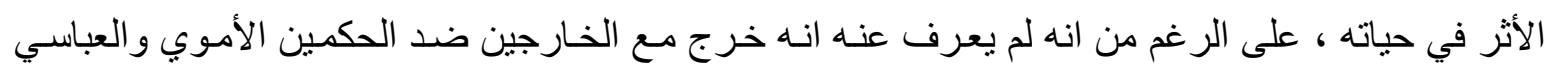

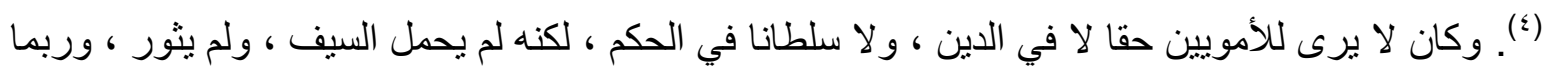

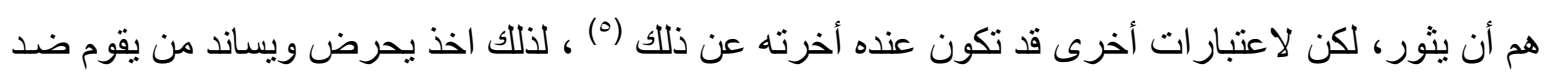

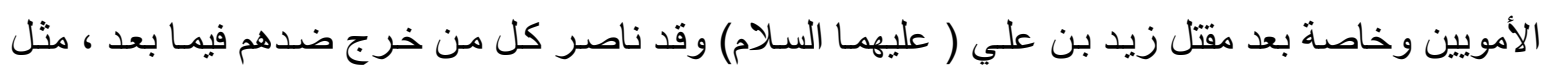

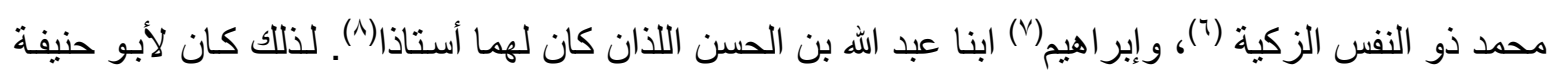
من ضـمن مو اقفه ، موقف مشـرف تجـاه زيد بـن علي ( عليهمـا السـلام ) حفظها لنـا التـاريخ، فقد كان مـن المناصرين و المحرضين على الدولة الأموية من اجل الثورة ضد الظلم و الطغيان ، وقد اتصل بـه ، واخذ منـه العلم ، وكان يتعصب له، ويميل إليه (9). وفي موقف أخر، ذكر : "شـاهدت زيد بن علي (عليهمـا السـلام) كما شاهدت أهله، فما رأيت في زمانه أفقه منهه ولا أسرع جواباً ولا أبين قو لا ، فقد كان منقطع القرين ، وكان بدعى بحليف القران" (·) (')

و أنشار أبو زهرة أن زيد بن علي (عليهـا السـلام) أرسل إلى أبي حنيفة، احد أصحابه ، وهو

الفضل بن الزبير (') بدعوه إليه لمناصرته و الخروج معه ضد الطغاة الأموبين في عهد هشام بن عبد الملك ، غير انه اعتذر ولم يستطع الخروج معه ، وقد قال للفضل : اعتذر لي عنده ، وكان يمده بالمعونـة المالية،

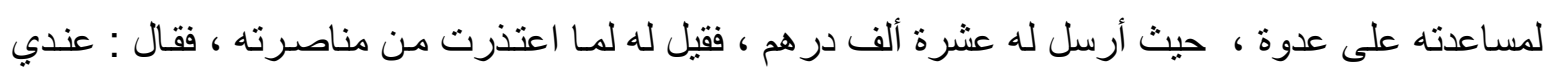
العديد من الودائع التابعة للأمة من الناس ، وقد عرضتنها على أبن أبي ليلى ، فاعتذر عن تأديتها ، ولو تم ذلك لكان غير ذلك ، وفخفخت أن أموت جاهلا وفي ذمتي ودائع الناس (r'). و وأرسل أبو حنيفة لزيد بن ابن علي

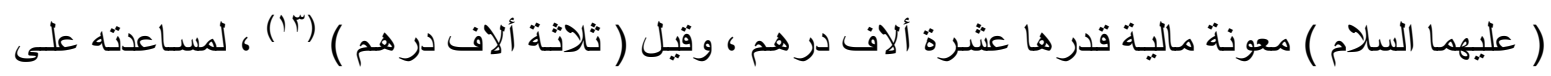
عدوه (ءٔ). وقال (رحمه الله) في مو اقف عديدة : إن خروج زيد بن علي (عليهما السلام) على حكم الأمويين،

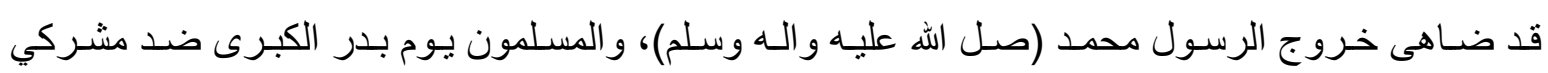

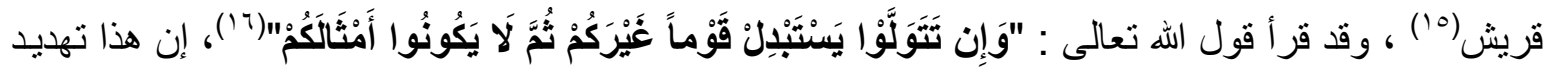

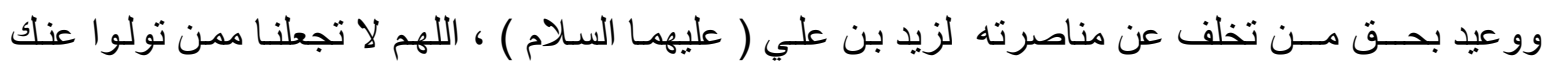


(IV) ، وبذلك يكون أعلنها صر احةً للناس بالمشاركة في الثورة التي قادهـا زيد بن علي (عليههـا السـلام) من

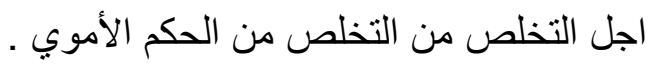

وبما انه نربي في بيت أهل للعلم والعلوم ، ومن درس على يد هؤلاء أصبحو ا من كبار الفقهاء

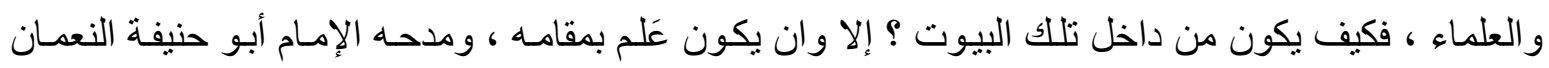

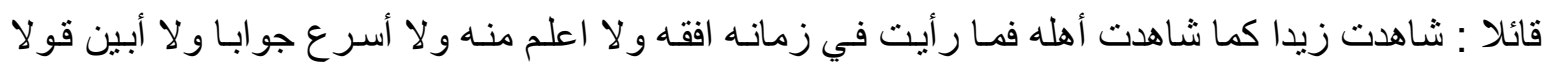
ـ و أثنار أبو حيان الأندلسي انه: "إن أبو حنيفة رحمه الله يفتى سر ا بوجوب نصرة زيد بن علي (عليهما

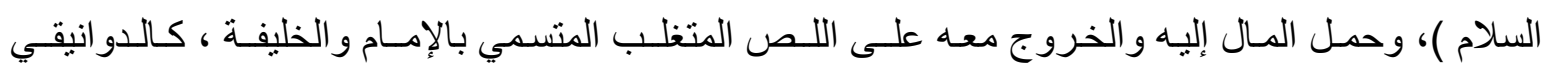

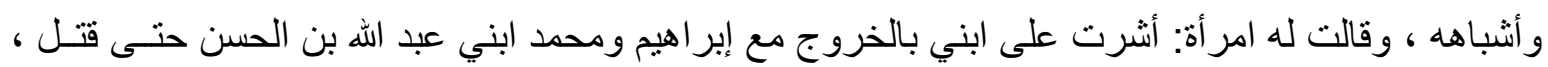
فقـال ليتني مكـان ابنك ،وكـان يقول في المنصور وأثنياعه لو أرادوا بنـاء مسجد وأرادوني على إنى عد أجره لما فعلت" (91) ، و المسمى الإمام اللص المتغلب ، هو هثام بن عبد الملك الخليفة الأموي الذبي ثار عليه زيد بن علي (عليهما السلام) و أما الدوانيقي، فهو الخليفة العباسي أبو جعفر ، سمي بذلك قيل لبخله (·r) و هذه الأخبار والروايات التي وصلتنا عن أبو حنيفة النعمان ، تدل على انه كان يرى إن الثورة على الأمويين أمر شرعي وجائز في الدين الإسلامي ، بشرط وجود الإمام العادل ، وان زيد بن علي (عليهما

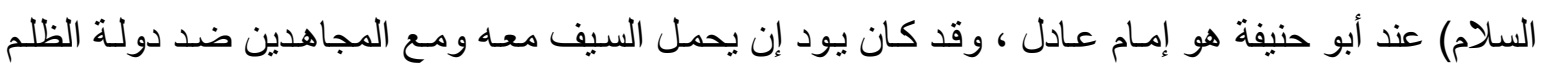

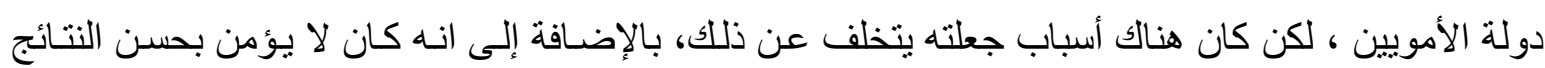
التي يمكن إن يحصل عليها الثائرون، وكذلك شكه في نية من بايع من أهل الكوفة وباقي المدة في استمر ارهم

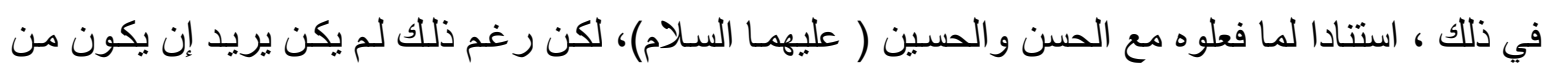
المثبطين و المعوقين ، فأرسل المعونة المالية للثورة ، لتكون دليل لتأيده ، وكما نعرف في المـال قوة ، ورغم ذلك عرض حياته للخطر ، وكان ذات إرادة وحزم وقوة وجريء ور ابط الجأش ولم يهن ولم يضعف على

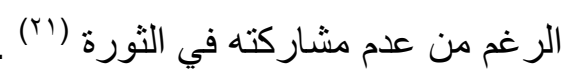

و إن أبو هبيرة (rr) عندما كـان و اليا على الكوفة جمع الفقهاء و العلمـاء ومنهم أبو حنيفة قد عرض عليه العمل معه فامتتع بل انه قال : والله لو دعوني لأعد أبواب واسط لمـا فعلت ، وكان يريد من

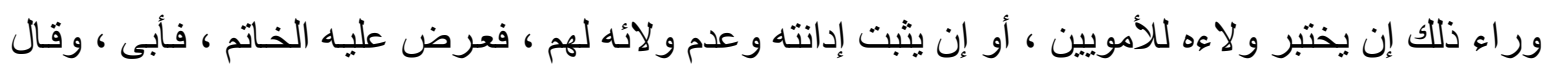

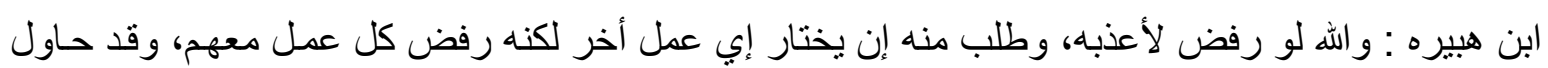
معه الفقهاء في إن يقبل من اجل سلامته ، ولكن كرر الرفض، و على الرغم من انه تعرض للضـرب الضه الثديد حتى انه تورم رأسه ، ولم تهن نفسه ، ولم يضعف إمام جلادياهولم تدمع عينـاه، لكن بكى عندما سمع أمسه قد فـ نالها الغم و التعب و الآلام بسبب اعتقاله من قبل السلطات الأموية ، و واشتد تضييق عليه ، وحتى ونى قيل إن هناك

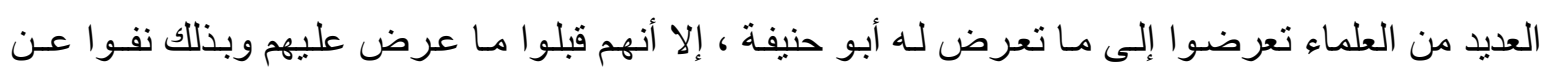
أنفسهم الريب ، وتخلصسو ا ممـا تورطوا فيـه ، أو لم يكن عندهم صبر كصبر أبو حنيفة (rآ).

كل هذه المصاعب التي تعرض لها أبو حنيفة ، لأسباب عده أهمها : مناصرته لزيد أبن علي (

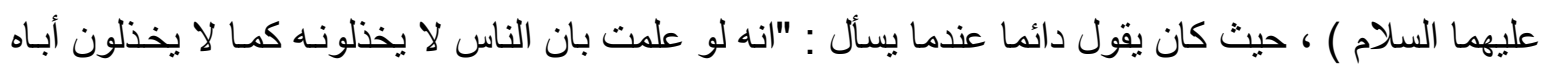


لجاهدت معه ، لأنه إمام حق ولكن أعينه بمالي" و ابنه يحيى الذي قتل في عهد الخليفة الأموي الوليد بن يزيد ، بعد أن أقام بثورة في الجوزجان، وكذلك مقتل ابن يحيى عبد الله الذي فر من اضطهاد الأمويين إلى اليمن ،

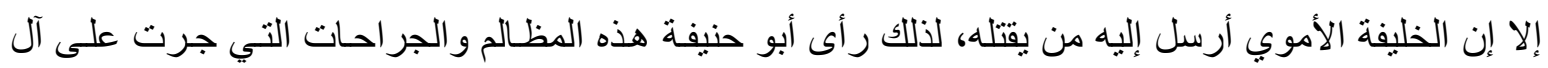
البيت ، ومن المؤكد إن لسانه قد تحدث عن تللك الظُلامات ، مع العلم انه كان احد تلاميذ زيد أبن علي (عليه

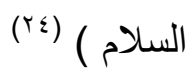

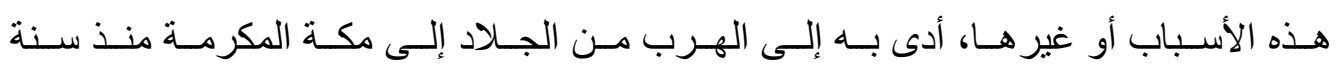

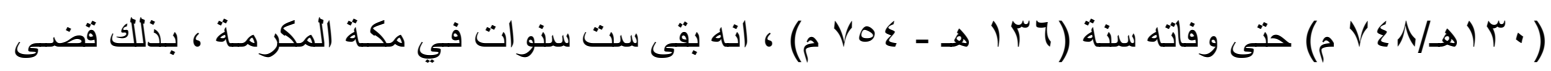
شطر امن حياته في جوار بيت الله الحر ام، عكف خلالها على دراسة الحديث الفقه و العلوم هنالك و التي ورثت علوم الفقهاء (ro) ـ لهذه الأسباب و غير ها، "روي أن محمد بن جعفر الصـادق ( عليه السـام ) قال: رحم الله

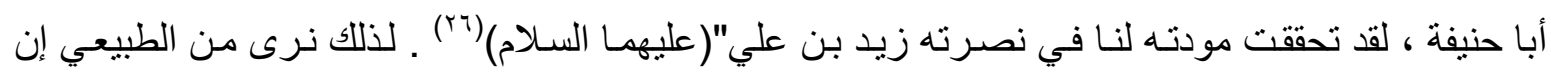

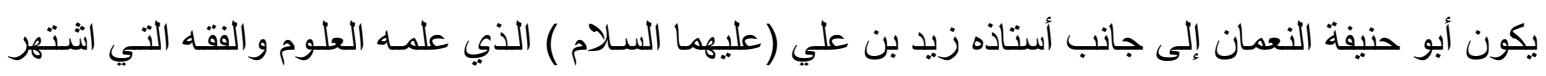

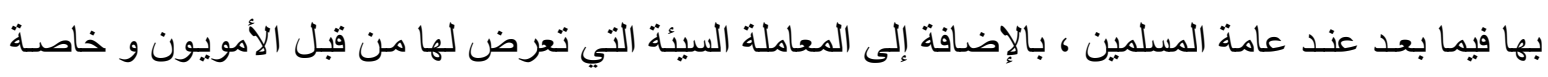

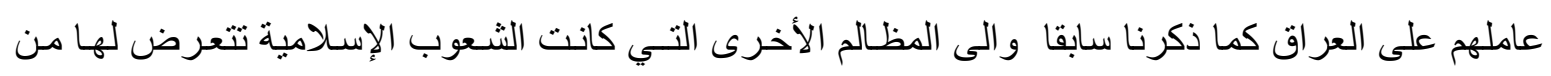

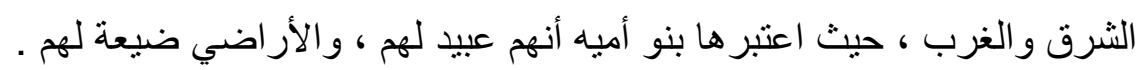
أبو إسحاق السبيعي (rV) ـ "ووصفه بأنه أفصح أهل بيته لِساناً و أكثر هم بيانـاً قائلاً : وقف التاريخ على نُبذة

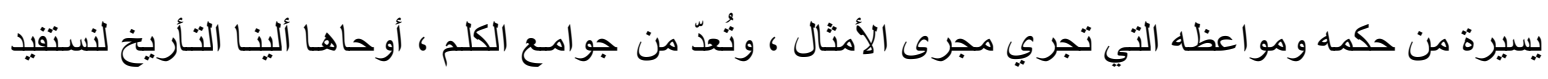

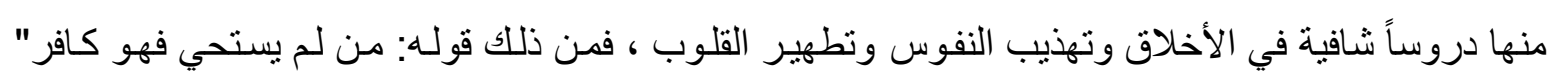

أبي المعمر(9") ـ يروي : إن زيد أبو الحسين بن علي بن الحسين بن أبي طالب ( عليهم السـلام )، كان تقيا

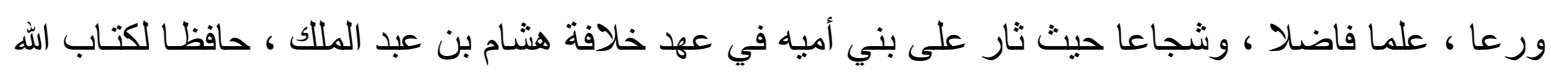
عز وجل ، ولسنة رسوله الأكرم محمد بن عبد الله (صل الله عليه و اله وسلم ) وقد لقب بالشهيد (·") . ابن الكردبوس ('ّ) و أنفرد المؤرخ ابن الكردبوس قائلا : بعد قتل زيد بن علي ( عليه السـلام ) ، وبأمر من الخليفة الأموي تم قطع رأسه وإرساله إلى الثام والأمصار العربية ، وصلبه جسمه عريانا ، وبعد ذلك الحدث لم يفلح هشام بن عبد الملك بعد ذلك أبدا ، ولم ينتفع سلطانه (r؟r) . عبد الرحمن ابن خلدون (rT) ـ إما الفيلسوف والمؤرخ الأندلسي ابن خلدون، فلم يخرج عن باقي المؤرخين

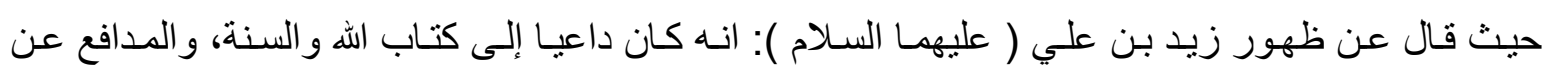
المستضعفين، وعطاء المحرومين و الفقر اء من الثعوب الإسلامية، والجهاد ضد الظالمين، و العدل في تقسيم الفيء على مستحقيه، ورد المظـالم التي لحقت بكافـة أطياف الثـعب وفي كل مدن الخلافــة الأمويـة، و أفعـال الخير ونصرة أهل بيت النبوة (عليهح السلام) (£ّ). 
ابن حجر العسقلاني("). و عند ترجمته لشخصية زيد بن علي ( عليهمـا السـلام ) يقول ابن حجر : هو أبو

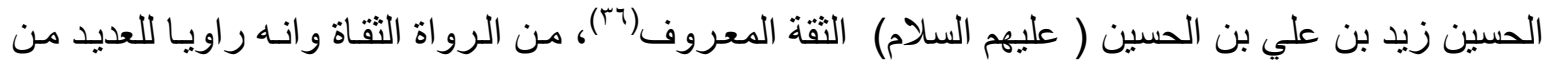
الأحاديث عن أبيه وجدة و عن آل بيت النبوة من أجداده ، و انه رأى الصحابة الذين كانوا مـع رسول الله (صل

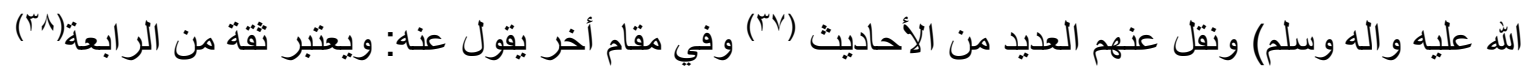
علي بن محمد بن احمد ابن الصباغ(ª). إما ابن الصباغ الذي فضل زيد بن علي (عليهمـا السـلام ) على بني

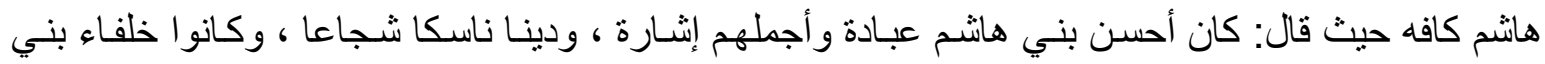
أمية يكتبون لعمالهم في العراق ، إن امنعوا أهل العراق والكوفة من حضور مجالس زيد بن علي ( عليهما السلام ) ، فان له لسانا ابلغ من الكهانة والسحر، و اقطع من غلبة السيف ، ومن النفذ في العقد ، واحد من شبا

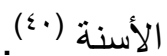

شمس الدين السخاوي ('ء). المؤرخ والفقيه وعالم الحديث والأديب المصري ، شمس الدين السخاوي افرد حديثا وقال : كان زيد بن علي ( عليهما السـلام ) ممن رفعت درجته في الآخرة عندما استشهـد بعد إن ثنار

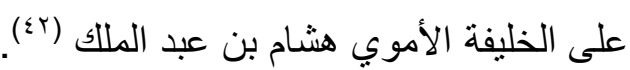
محمد أبو زهرة ـ انفرد الفقيه والمؤرخ المصري الكبير محمد أبو زهرة ، عن العديد ممن عاصر هم ، بذكر أهم صفات الإمام زيد بــن علي (عليهما السلام) ، حيث أوصله إلى مصـاف أئمـة آل البيت ، فقال: انـه كـان يتمتع بصفات تنازع بها إلى العلم الصافي والمعارف التي اكتسبها من أجداده ، آل بيت النبوة الكر ام ( عليهم السلام)، وتللك هي صفات الصفوة منهم ، فكانت السجايا العلمية الكريمة والمواريث العلمية التي ورثها هؤلاء الأكرمون ، وكأنهم تجري في أناسهم كما أنها تجري في عروقهم الدماء الطـاهرة الزكية ، ومـا من صفة من

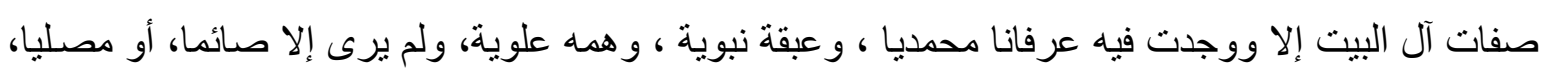
أو قارئا للقران (r)

كان زيد بن علي ( عليهما السلام ) نشاء من سلاله طاهرة زكية ، فأبوه علي ( عليه السلام )

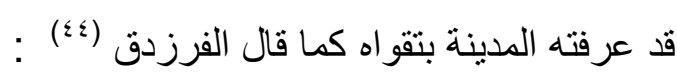

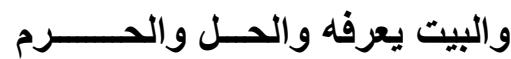
هذا التقى التقي الطاهر العلــم أمست بنور هداه تهتدي الظلم

\section{"هذا الذي تعرف البطحاء وطأتـــــــه}

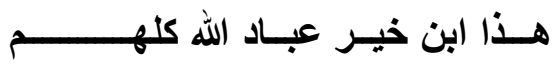

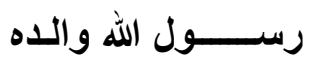
هـــنا علـ

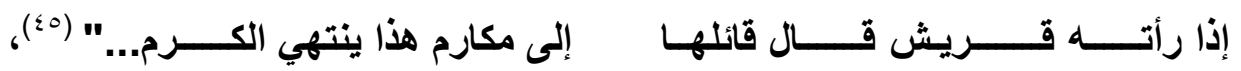

وجده أبو الثهداء الحسين ( عليه السلام)، وجده الأعلى أمير المؤمنين علي (عليه السـلام)، بـاب مدينة العلم علم الرسول ، واخو النبي ( صل الله عليه واله وسلم ) في المؤاخـاة التي عقدها في المدينـة بعد الهجرة إليهاب(؟). ويضيف ويقول وكان له الحظ الأوفر من الإخلاص، فدفعة الإخلاص إلى طلب العلم وان يهاجر إلى شتى المدن الإسلامية، وكانت أول ثمرات الإخلاص هو التقوى ، مما جعلته إن يستشعر دائمـا من خشية

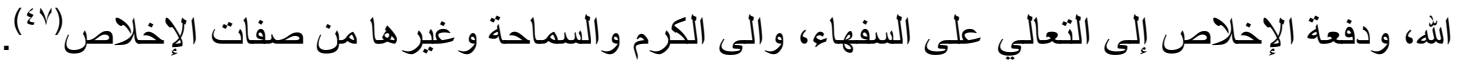


كذلك أتاه الله عز وجل الثجاعة في الحرب، وقبلها الثجاعة الأدبيـة التي كان بشهد بها العدو

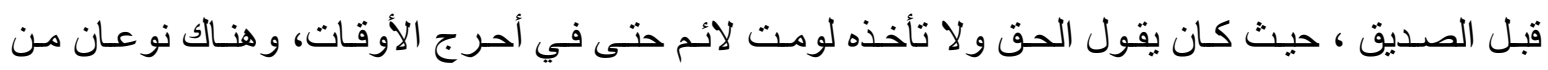

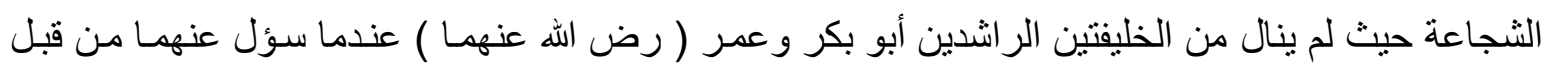
بعض أصحابه ، إمـا النوع الأخر من شجاعته فهو بعد إن تخاذل أصحابة الذين بايعوه و الذي اختلف في وني

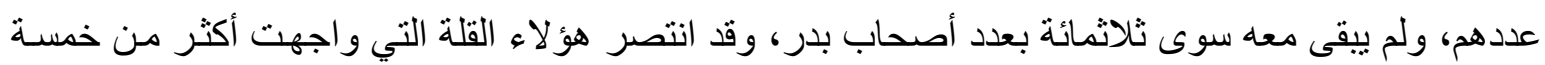

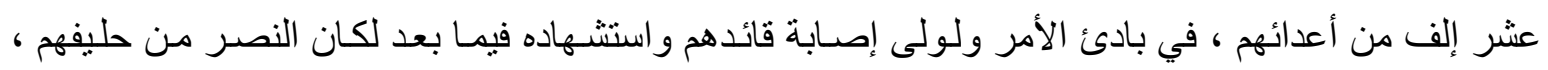

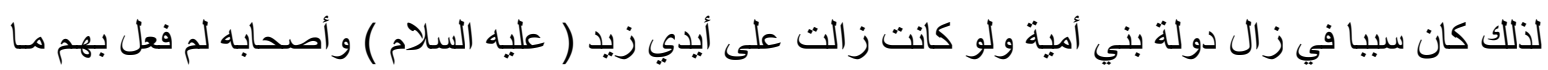

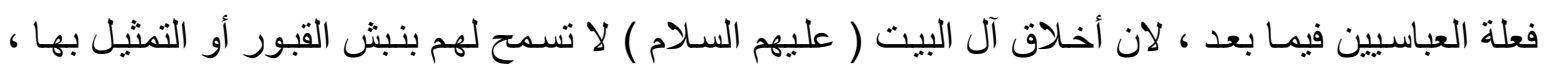
فانزلوا نقمت سيوفهم بالأمويين ، وقد كان شديد الإباء و الصبر على الثدائد ، وقد ذكر أبو زهرة العديد من

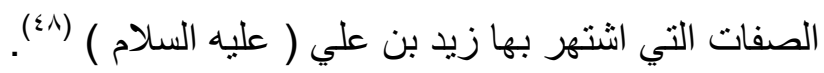

يوسف العش (9؛) ـ كان يدعوا إلى كتاب الله والسنة ، والى العدل بين الناس ، ورفع الظلم و الجور، وكان

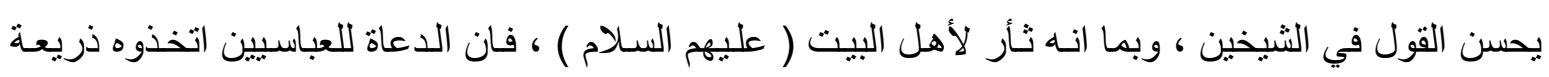

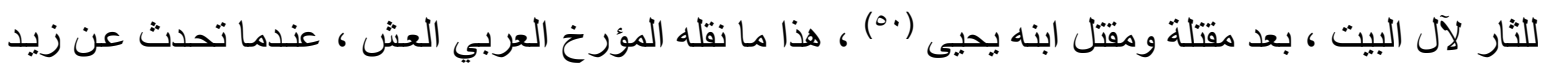
بن علي ( عليهما السلام ) .

محمد الصلابي ـ على الرغم من الاختلاف في المذهب بين المؤرخ الليبي المعاصر محمد الصـلابي وبين

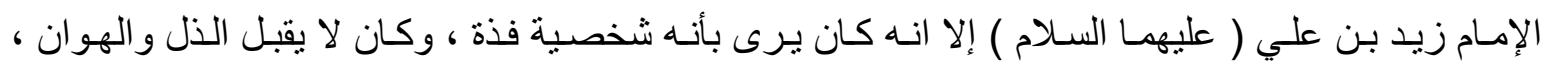

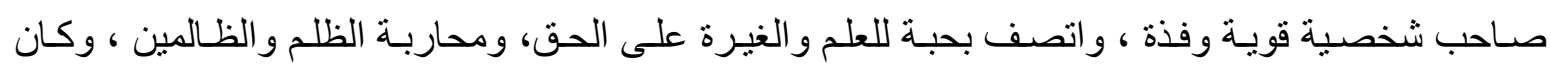
علومه وفقهه من علم وفقه جده الإمـام علي (عليه السـلام ) ، و وهو ينفي إي الصـلابي اتصـاله بو اصل بـن عطاء ، وسبب ذللك كما يقول: كيف يأخذ علومه من شخص مبتدع ، وان الخلاف بينهما خلاف جو هري ، فلا يمكن إن يجتمع الرجلان على مذهب واحد ، وكيف يقبل أخيه الإمـام الباقر ( عليه السلام) هذا العمل ، وهو وهو بعد ذلك يثني عليه ، و انه ثار ضد الظلم وتحول الحكم إلى الور اثنة ، وبسبب سفلك الدماء ، واستخدام العنف

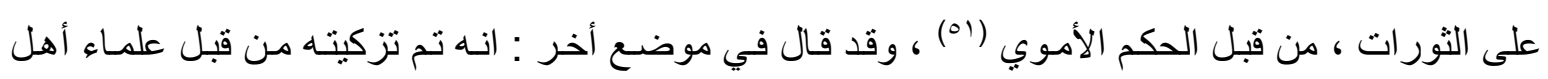

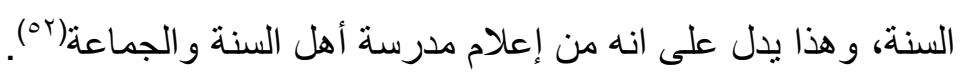

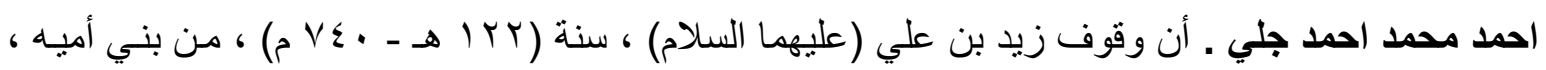

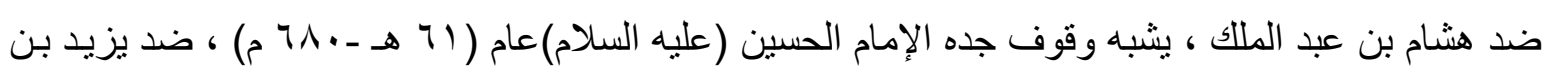

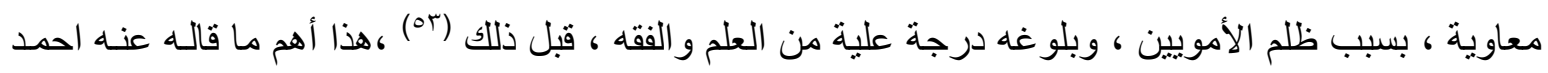

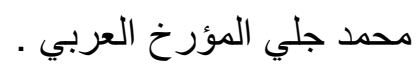
يوليوس فلهوزن (\&) . أما إذا ذهبنا إلى غير العرب ، فإننا نجد العديد من الكلمات التي تشـر القارئ بوقفة احتر ام وتبجيل استتر افي لتلك الثخصية ، فالمستشرق الألماني فلهوزن ، قال عن زيد بن علي ( عليهما السلام ) : أن مصر عه احدث تغير اكبير عند أولئك الذين عاهدوا أن ينصروه ، عند بدايـة دعوته ، ومن ثم كن

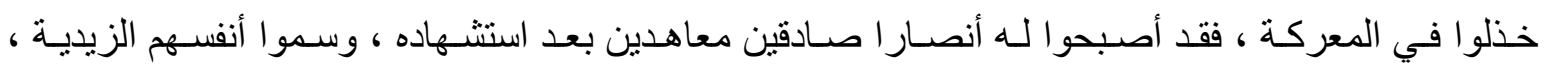


و أصبح مصيره كمصير جده الحسين بن علي ( عليهــا السـلام ) (00) ، وعلى الرغم من أن ثورتـه كانت نهايتها يرثى لها، إلا أنها كانت لها شأنها بين الثنورات الثيعية التي أعقبتها، وتلك الثورات كانت السبب في

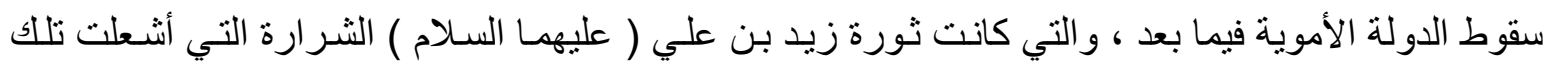
الثورات (07)

\section{-}

* يتضح من ذلك أن الثائر زيد (عليه السلام) شخصية مميزة من رجالات ، آل بيت النبوة (عليهم السـلام) ، و أفاضـل علمـائهم و أكـابر فقهائهـا وداع دعاتها، وصـاحب الألقـاب المبجلـة عندـ المعصـومين (عليهم السـلام) وسائر بنو هاثم (حليف القران ، زيد الازياد ، الثهيد ، أبو الحسين ) ، ألقاب لا سبيل لمنحها إلا لمن أوتي من العلم شيئاً كثيرًاً ، وحاز على الرضا والتقدير و التبجيل ، و أخذ العديد من العلماء و الفقهاء اخذوا من العلوم الفقهية والأحاديث المروية عن الثائر زيد (عليه السلام) .

* تلك الثخصية التي هي قبس من شخصية أجداده وخاصـة شخصية جده الإمـام الحسين بن علي (عليهم السـلام) ومشكاة مـن والدة السـاد (عليـه السـلام) ، وصـورة مـن أخيـه وابـن أخيـه البـاقر والصـادق (عليهمـا

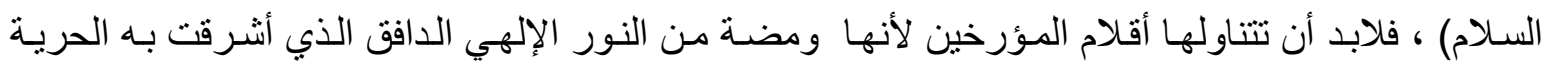
و الكر امة ، وتمثل الأنموذج الحي للتجربة الو اقعية للإسلام الصـافي بكل مفاهيمـه وتعاليمـه و أهدافه في نطـاق الإر ادة الإلاهية بعد ثورة جده الإمام الحسين بن علي (عليهما السلام) .

(')"عامر بن شر احيل أبو عمرو الثعبي من شعب هددان علامة أهل الكوفة ولا في وسط خلافة عمر بن الخطاب وروى عن الإمام علي

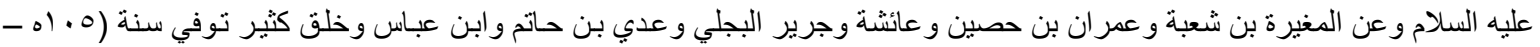

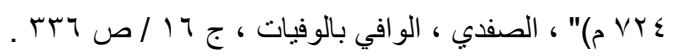

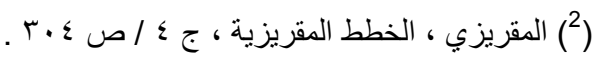

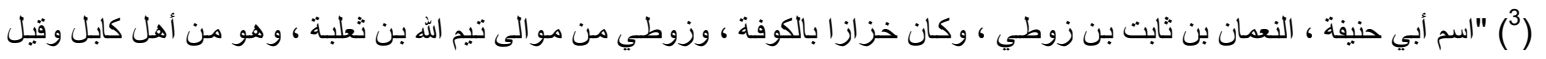

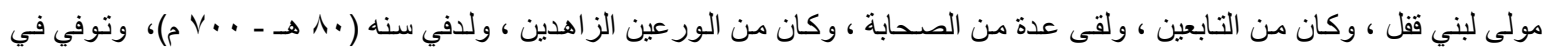

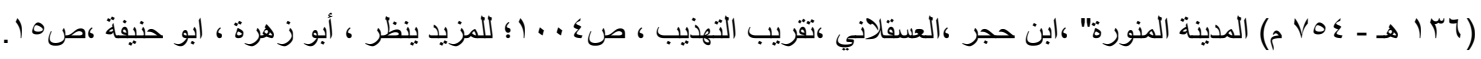

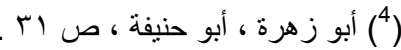

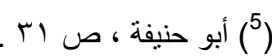

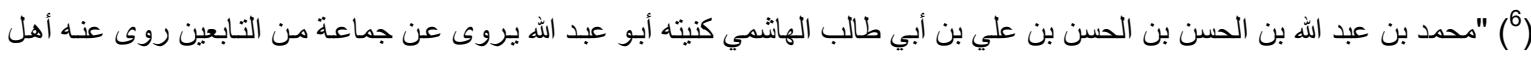
الدينة أمه هند بنت أبي عبيدة بن علي بن ربيعة بن الأسود الأسيدي قتل بالمدينة سنة (

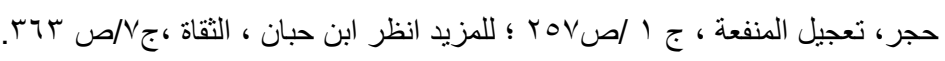

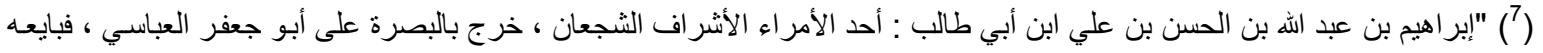

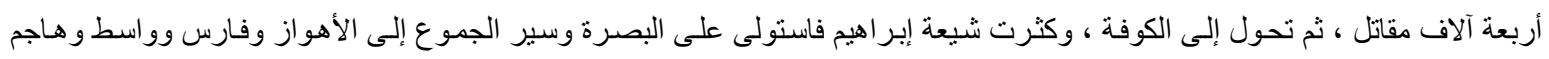

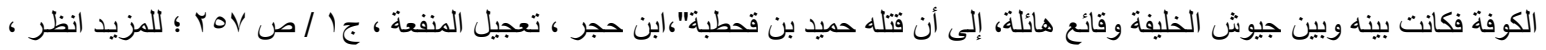

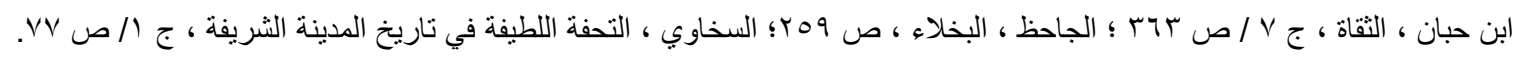

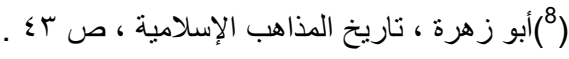

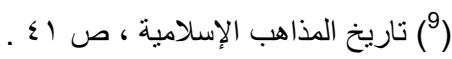

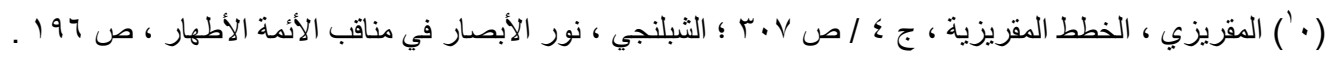


('1) "الفضل بن الزبير الرسان ،من أصحاب الإمام أبو عبد الله الصادق(عليه السلام)" ، التفرشي، نقد الرجال ،ج ع/ ص. r.

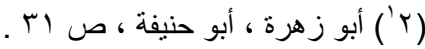

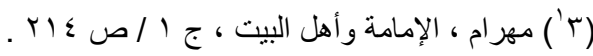

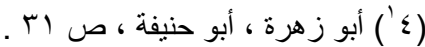

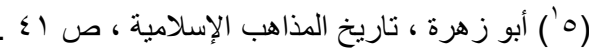

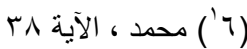

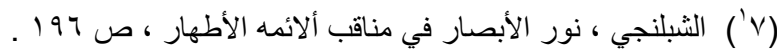

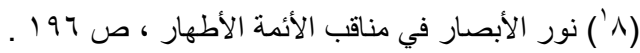

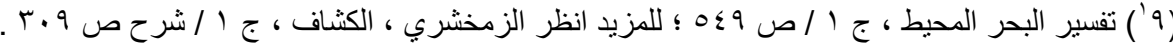

(

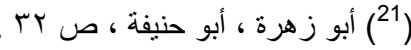

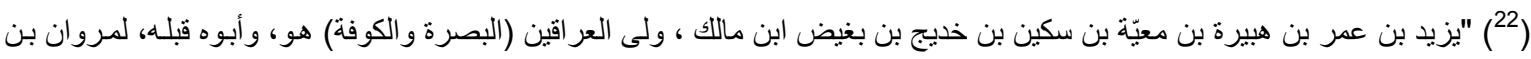

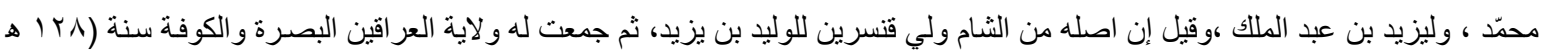

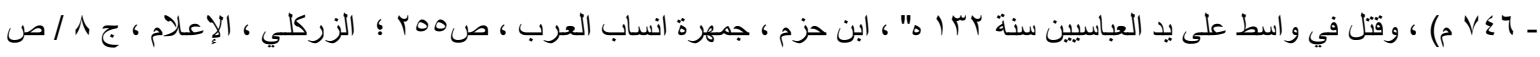

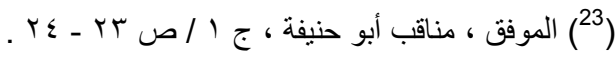

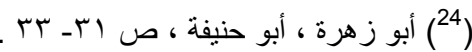

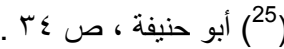

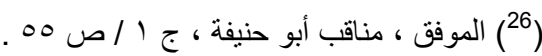

(27) "أبو إسحاق عمرو بن عبد الله بن علي بن أحمد بن ذي يحمد بن السبيع السبيعي الهمداني الكوفي من أعيان التابعين رأى عليا عليه

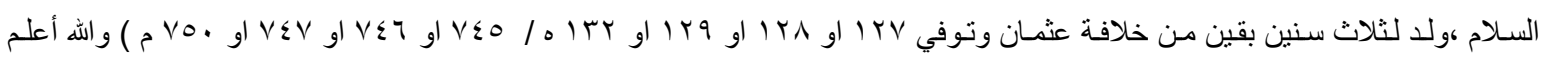

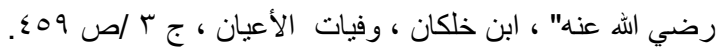

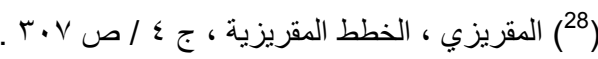

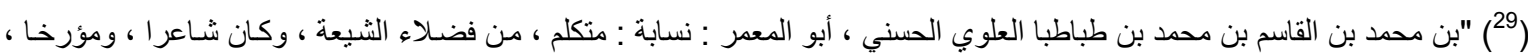

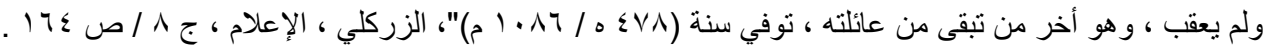

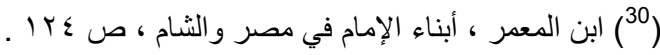

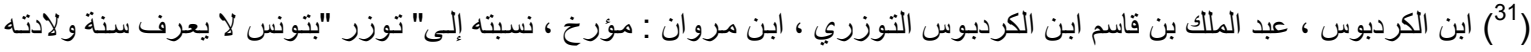

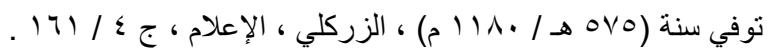

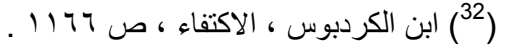

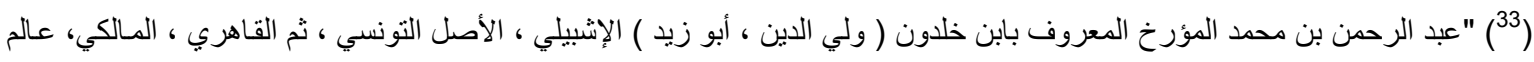

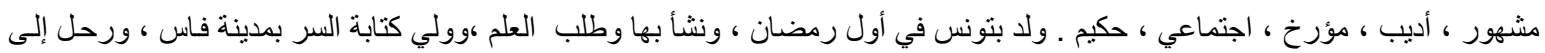

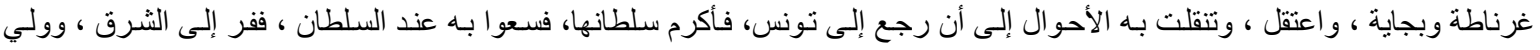

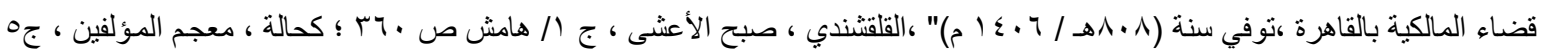
/ ص 1199.

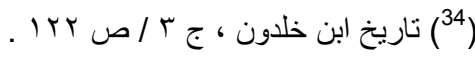

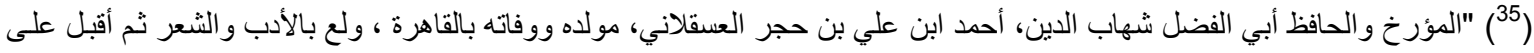

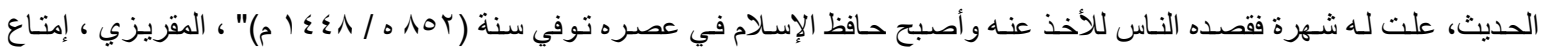

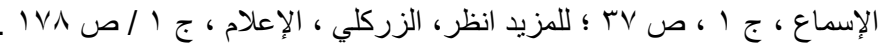

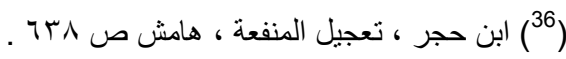

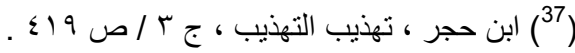

$$
\begin{aligned}
& \text { (38) }
\end{aligned}
$$




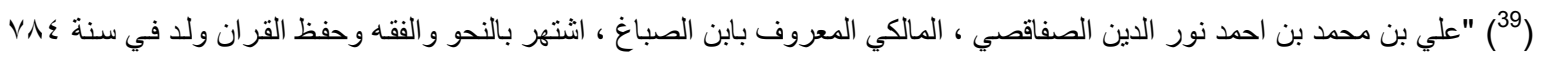

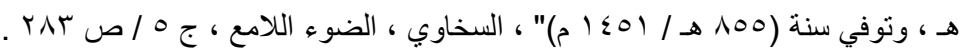

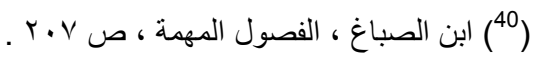

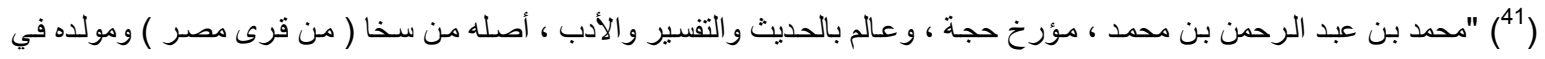

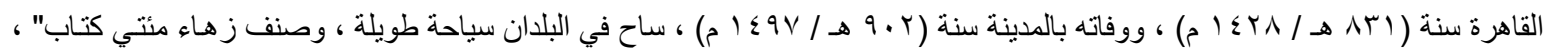

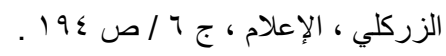

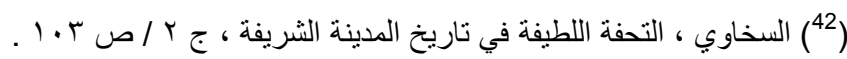

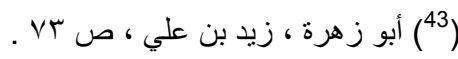

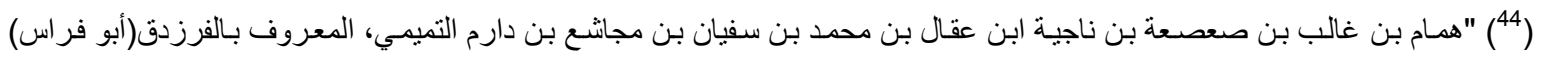

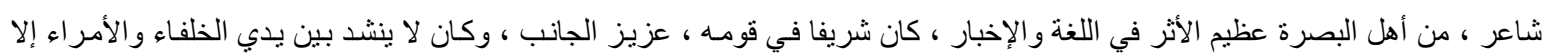

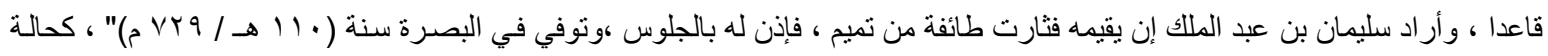

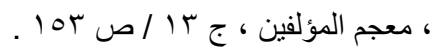

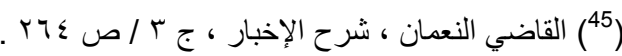

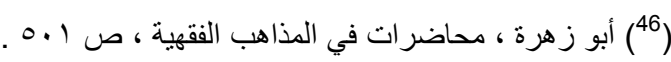

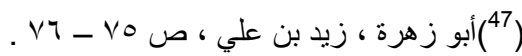

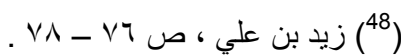

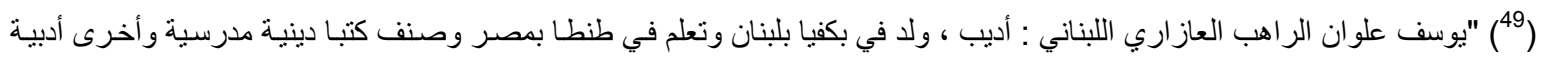

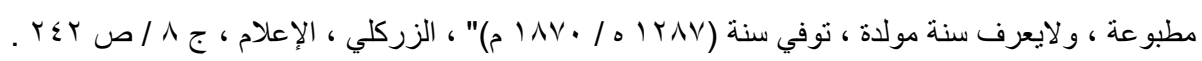
(

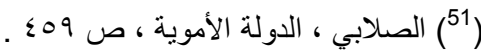

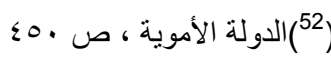

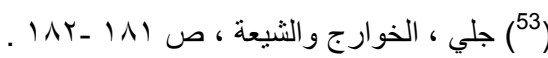

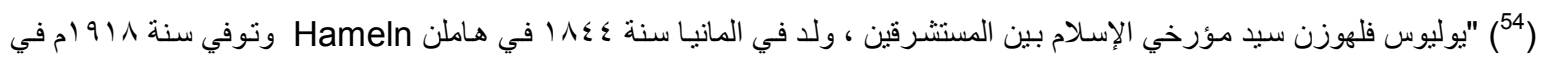

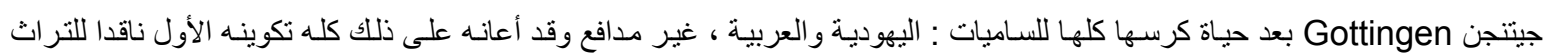

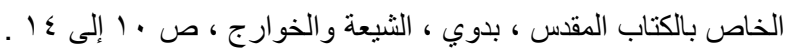

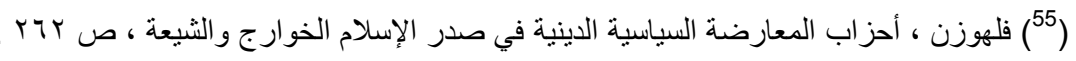

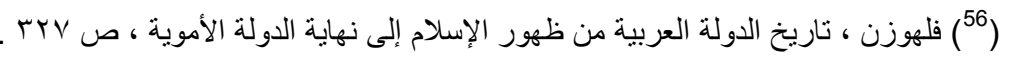

المصادر والمراجع

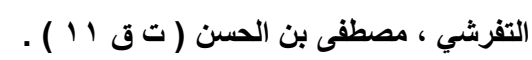

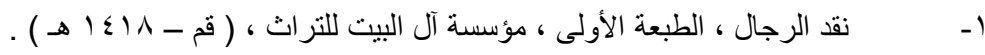

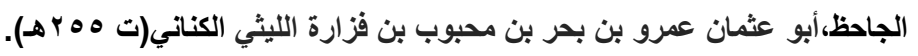

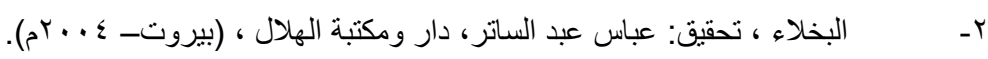

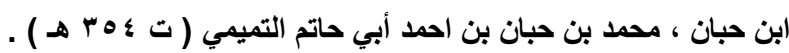

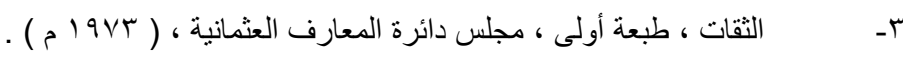

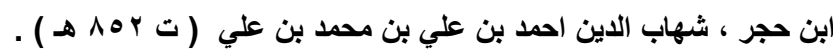

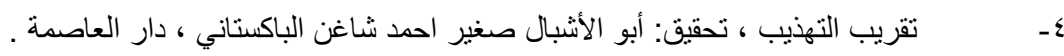

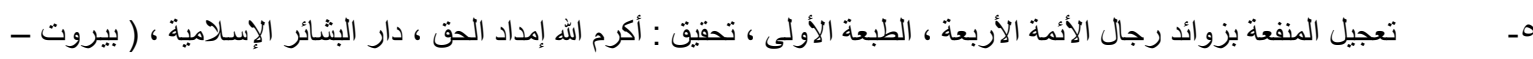
. ( $) 1997$

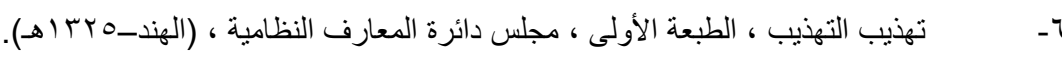

ابن حيان الأندلسي،محمد بن يوسف بن علي بن يوسف بن حبان بشير الدين(ت ه ؛ ع هـ). 


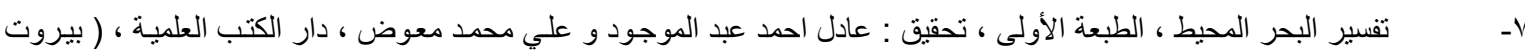

$$
\text { . ( }) \text { r...- }
$$

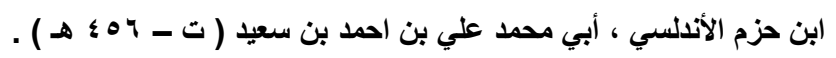

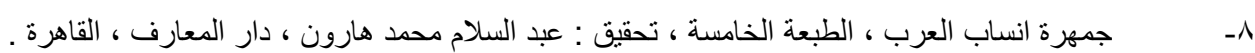

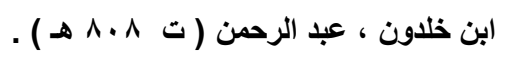

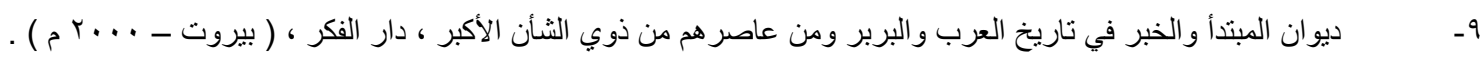

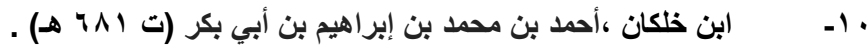

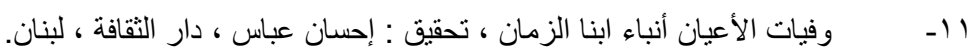

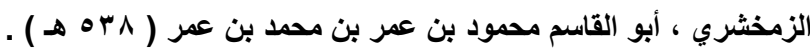

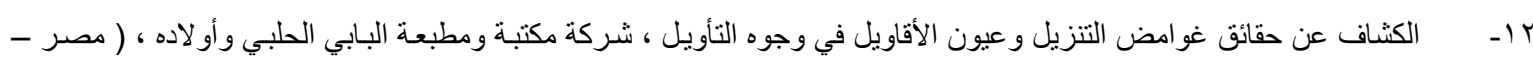
. ( ) 1974 السخاوي ، شمس الدين أبو الخير محمد بن عبد الرحمن بن محمد بن أبي بكر بن عثمان بن محمد ( ت ب ـ 9 هـ ) .

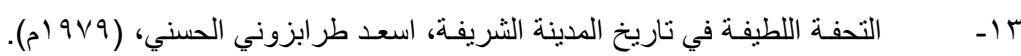

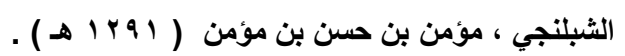

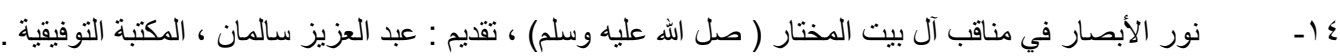

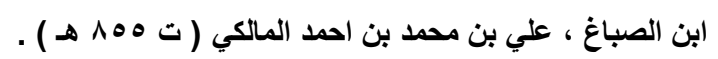

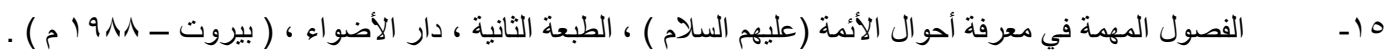
الصفدي ، صلاح الدين أبو الصفاء خليل بن أيبك بن عبد الله الألبَكِي الفاري ( ت ع ؟ ؟هـ).

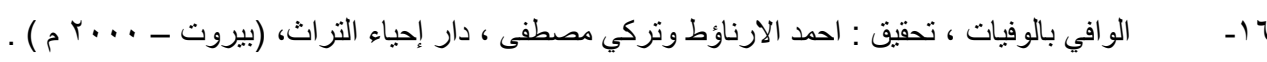

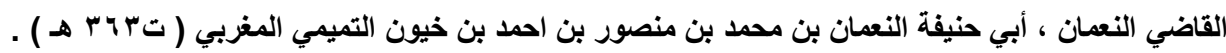

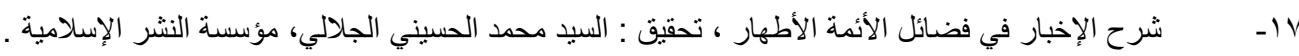

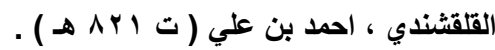

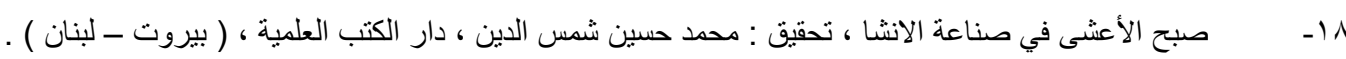

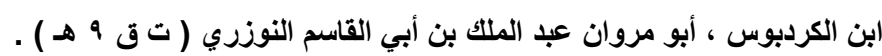

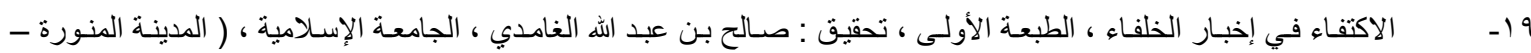

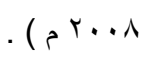
المقريزي ، تقي الدين احمد بن علي ( ت ه ؛ ع هـ ) .

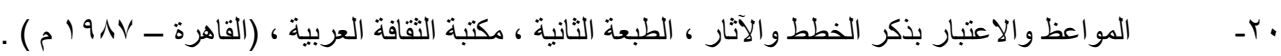

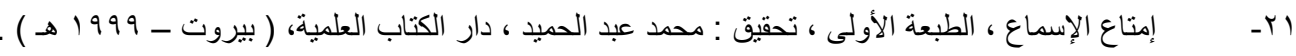

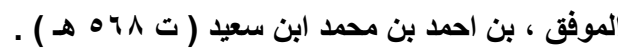

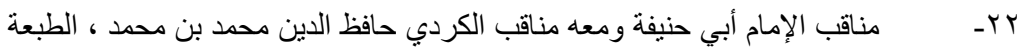
المراجع . (1) البدوي ، عبد الرحمن . البر .

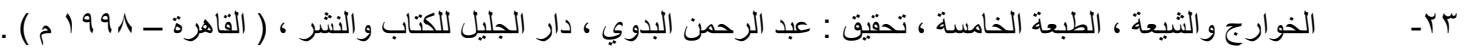
جلي ، احمد محمد احمد.

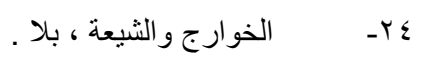

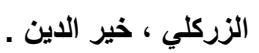

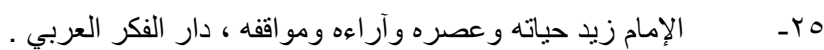

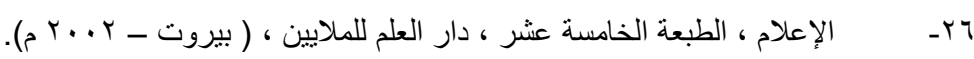

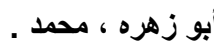

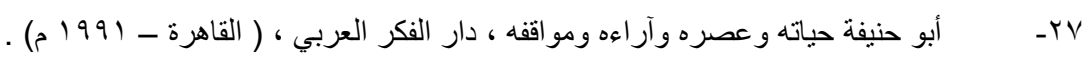

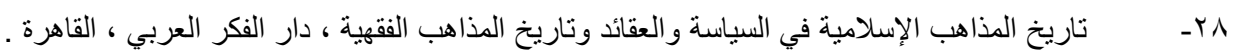




$$
\begin{aligned}
& \text { 9 - محاضرات في تاريخ المذاهب الفقهية ، معهد الدراسات الإسلامية ، مطبعة المدني ، مصر. }
\end{aligned}
$$

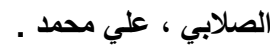

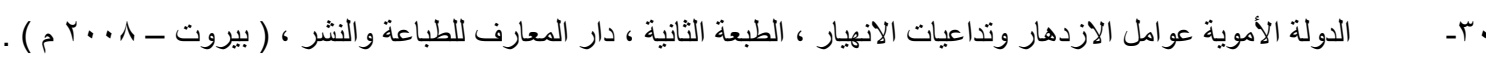
العش ، يوسف . (الث

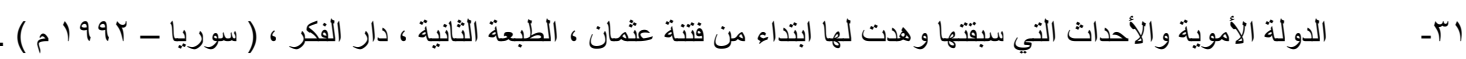
كحالة ، عمر .

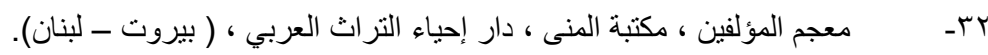

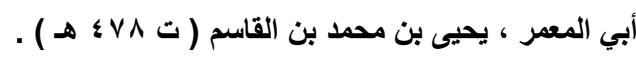

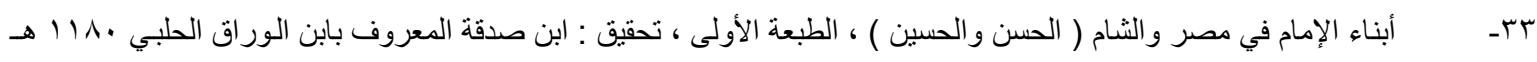

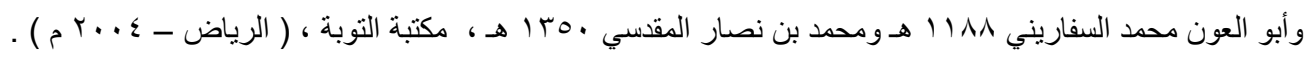
مهرام . محمد بيومي .

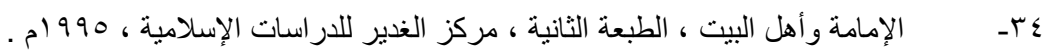
مراجع أجنبية.

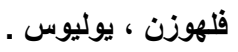

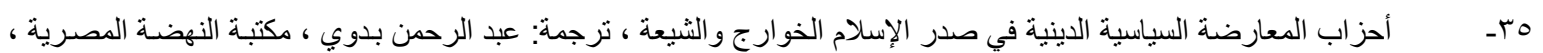

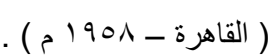

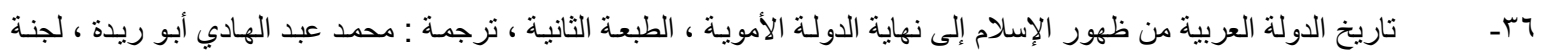
التأليف والترجمة ، ( القاهرة - 1971 ) ) . 